\title{
El cacao en la Costa ecuatoriana: estudio de su dimensión cultural y económica
}

\author{
Cocoa on the Ecuadorian coast: \\ a study of its cultural and economic dimension \\ O cacau no litoral equatoriano: \\ estudo de sua dimensão cultural e econômica
}

\author{
Andrés Abad \\ Escuela Politécnica Nacional (Quito, Ecuador) \\ andres.abad@epn.edu.ec \\ http://orcid.org/0000-0001-8834-0218 \\ Cristina Acuña \\ Escuela Politécnica Nacional (Quito, Ecuador) \\ cristina.acuna@epn.edu.ec \\ https://orcid.org/0000-0002-7286-6140 \\ Efraín Naranjo \\ Escuela Politécnica Nacional (Quito, Ecuador) \\ efrain.naranjo@epn.edu.ec \\ https://orcid.org/0000-0001-6629-1101
}

DOI: https://doi.org/10.32719/25506641.2020.7.3

Recibido: 1 de septiembre de 2019 - Revisado: 20 de octubre de 2019 Aceptado: 4 de noviembre de 2019

Artículo de investigación

Licencia Creative Commons

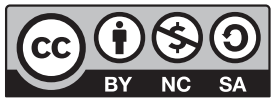




\section{Resumen}

Este artículo presenta cronológicamente hechos histórico-culturales y económicos del cacao en Ecuador. Por intermedio de la metáfora del tejido, se establece una doble mirada de su historia, considerando que ha sido uno de los productos primarios de exportación más importantes del país. Esta investigación tiene por objetivos describir los principales elementos culturales y económicos de la historia del cacao en la Costa ecuatoriana, y coadyuvar en la comprensión de la articulación de estas dimensiones. Se basa en el método descriptivo, con técnicas de análisis documental y bibliográfico en perspectiva histórica, para evidenciar la trascendencia acerca del sentido cultural del cacao vinculado con su aspecto económico. Según la metáfora aquí planteada, la urdimbre del tejido del cacao se relaciona con los factores menos evidentes, los aspectos histórico y cultural del producto; la trama, que es lo más visible, corresponde al contexto económico y comercial del cacao. El artículo señala algunos elementos que conforman las dimensiones de análisis y que podrán servir para profundizar sobre la magnitud o dirección de sus interrelaciones.

Palabras clave: Cacao, Ecuador, cultura, economía, metodología descriptiva.

JEL: Z1 Economía cultural.

\section{Abstract}

This article presents chronologically historical-cultural and economic facts of cocoa in Ecuador. Through the metaphor of the fabric, a double look of its history is established, considering that it has been one of the most important primary export products of Ecuador. This research aims to describe the main elements of the cultural and economic dimension related to the history of cocoa on the Ecuadorian coast and helps in understanding the articulation of these dimensions. It is based on the descriptive method with the techniques of documentary and bibliographic analysis in historical perspective, to demonstrate the importance of the cultural sense of cocoa linked to the economic aspect of the product. The metaphor presented here indicates that the warp of the cocoa fabric is related to the less visible factors and refers to the historical and cultural aspects of the product; the plot, which is the most visible, corresponds to the economic and commercial context of cocoa. The article highlights some elements that make up the dimensions of analysis and that may serve to deepen the magnitude or direction of their interrelations.

Keywords: Cocoa, Ecuador, culture, economy, descriptive methodology.

JEL: Z1 Cultural Economics.

\section{Resumo}

Este artigo apresenta cronologicamente fatos histórico-culturais e econômicos do cacau no Equador. Através da metáfora do tecido, estabelece-se um olhar duplo de sua história, considerando que foi um dos produtos primários de exportação mais importantes do Equador. Esta pesquisa tem por objetivo descrever os principais elementos da dimensão cultural e econômica relacionada com a história do cacau no litoral equatoriano e coad- 
juvar na compreensão da articulação destas dimensões. Baseia-se no método descritivo com técnicas de análise documental e bibliográfica em perspectiva histórica para evidenciar a transcendência acerca do sentido cultural do cacau vinculado com o aspecto econômico do produto. A metáfora aqui apresentada mostra que a urdidura do tecido do cacau se relaciona com os fatores menos visíveis e se refere aos aspectos histórico e cultural do produto; a trama, que é o mais visível, corresponde ao contexto econômico e comercial do cacau. $\mathrm{O}$ artigo põe em evidência alguns elementos que conformam dimensões de análise e que poderão servir para aprofundar a magnitude ou a direção de suas interrelações.

Palavras-chave: Cacau, Equador, cultura, economia, metodologia descritiva.

JEL: Z1 Economia cultural.

\section{Introducción y aspectos metodológicos}

E 1 cacao ha tenido un rol importante en la economía e historia ecuatorianas: junto con el banano y el petróleo constituyen la tríada más importante de productos primarios de exportación, elementos clave para la articulación del Ecuador con la economía mundial (Acosta 2006; Larrea Maldonado 2006; Henderson 1997). Adicionalmente, el impacto del cacao en la economía ha configurado elementos sustanciales que conforman la cultura en la Costa del país (Larrea Maldonado 2006; Chiriboga 2012). Esta investigación, de carácter introductorio, se centra en el cacao, y tiene por objetivo coadyuvar a la comprensión sobre la articulación entre las dimensiones cultural y económica de este producto en la región del litoral ecuatoriano. Surge con el fin de entender el fenómeno del cacao con una mirada doble, que pone en evidencia la necesidad de una articulación entre estas dos dimensiones.

Morgan (1990) señala que las metáforas sirven para entender lo complejo y lo paradójico de los aspectos de la vida social y organizacional, para poner atención en diversos atributos que damos por sentado y, en consecuencia, conseguir la comprensión de aspectos que pueden coexistir de modo complementario. Bajo dicha óptica se usa como estrategia de investigación la metáfora del tejido, compuesto por una urdimbre, que es el valor histórico y cultural del producto, y por una trama, que se refiere a los factores económicos asociados. La urdimbre, si bien es la que soporta vigorosamente un tejido, está en su mayor parte invisibilizada; mientras que la trama, que es 
de donde se generan las imágenes y los colores, es más visible. Esto permite contar con una mirada doble del tejido que conforma una unidad, en este caso de economía y cultura.

Para Tolila (2007), abordar la economía y la cultura no es fácil ni tampoco inmediato. Lleva en primer lugar a abordar el carácter histórico de las preguntas que se plantean y que se encaminan hacia un enfoque estratégico de las grandes interrogantes económicas. Esta doble mirada de la metáfora permite preguntarse sobre las dimensiones económicas de la cultura y las dimensiones culturales de la economía.

Este estudio, desde el punto de vista metodológico, tiene una naturaleza descriptiva: inicia con una recopilación y síntesis de bibliografía y documentos que permiten conocer cómo el cacao ha incidido e incide en la cultura y economía ecuatorianas, así como revisar la existencia de varios auges económicos relacionados con el producto. Para el efecto, se dio preferencia a los textos de referentes en el estudio sobre la incidencia del cacao en la economía ecuatoriana, así como a diversos artículos que se refieren a las últimas investigaciones arqueológicas sobre la domesticación del cacao en la Amazonía sur ecuatoriana, y a otros con datos de relevancia cultural. Posteriormente, se realizaron entrevistas para recopilar criterios de especialistas en torno a la relación entre la cultura y la economía del cacao en Ecuador, lo que permitió determinar algunas potencialidades existentes relacionadas con el cultivo, el procesamiento y la exportación del producto, así como con la fabricación de su principal derivado: el chocolate. Todo esto, con el objetivo de encontrar cuáles son los elementos de mayor importancia cultural y económica de este producto primario de exportación en Ecuador.

La estructura de este trabajo parte de una revisión bibliográfica y documental sobre el tema y subraya, en su primera parte, la importancia del significado histórico y cultural del cacao como producto primario de exportación en el país, desde sus orígenes culturales prehispánicos hasta la tradición colonial y republicana atada a él. En la segunda parte, se señalan las potencialidades económicas que, viniendo desde el pasado, se muestran en el presente, toda vez que los datos establecen que el chocolate elaborado con cacao ecuatoriano tiene gran aceptación y prestigio en el mercado mundial, por la calidad y la variedad de sus productos. Finalmente, con la descripción de las dimensiones y los elementos que las conforman, queda establecida de 
forma implícita su articulación, pues al igual que en la metáfora del tejido estas dos dimensiones se nutren recíprocamente.

\section{La urdimbre: significado histórico y cultural del cacao en Ecuador}

América Latina es conocida como la cuna del cacao. Por muchos años se ha reconocido a México y Centroamérica como zonas de domesticación de este producto, ya que se ha encontrado evidencia de su uso que data de más de cuatro mil años. Sin embargo, hoy existen investigaciones que señalan que al menos una variedad de cacao fino de aroma tiene su punto de origen en la Amazonía ecuatoriana.

Varias investigaciones (Zarrillo et al. 2018; Loor et al. 2009 y 2012) dan cuenta de la antigüedad del uso cultural del cacao (o Theobroma cacao $L$.) y reconocen que los antiguos pobladores de lo que hoy se conoce como la cultura Mayo Chinchipe, en el actual Ecuador, fueron los primeros en el mundo en utilizar la planta de cacao con fines alimenticios, hace aproximadamente 5.300 años. La revista Nature Ecology \& Evolution, en octubre de 2018, publicó "The Use and Domestication of Theobroma Cacao During the mid-Holocene in the Upper Amazon", cuya autoría pertenece a 19 investigadores, entre ellos el arqueólogo ecuatoriano Francisco Valdez, investigador del Institut de Recherche pour le Développement (IRD). Su resumen da cuenta de lo siguiente:

Tradicionalmente, se cree que el cacao se domesticó por primera vez en Mesoamérica. Sin embargo, la investigación genómica muestra que la mayor diversidad de T. cacao se encuentra en la región superior del Amazonas en el noroeste de Sudamérica, apuntando a esta región como su centro de origen. A nuestro entender, estos hallazgos constituyen la evidencia más temprana del uso de T. cacao en las Américas y el primer ejemplo arqueológico inequívoco de su uso precolombino en América del Sur. (Zarrillo et al. 2018, 1879)

Este estudio revela que la cronología de los primeros usos del cacao se mueve por lo menos 1.500 años atrás de lo que se sostenía en los círculos científicos (Zarrillo et al. 2018), pues luego de realizar pruebas científicas de 
laboratorio a las muestras de residuos alimenticios obtenidos en la zona, se confirmó la presencia de teobromina, cafeína y teolímina, elementos que se encuentran de manera simultánea en el cacao.

Es así que "los árboles de cacao, sus vainas, semillas y bebidas también estaban íntimamente relacionados con sus mitos y dioses", especialmente porque su "pulpa se come como un aperitivo vigorizante, que se convierte en un jugo fresco y se fermenta para hacer una bebida alcohólica utilizada en rituales y celebraciones" (Zarrillo et al. 2018, 1882). Además, las semillas de cacao fueron un elemento importante en el intercambio comercial entre los pueblos prehispánicos del litoral de la Costa ecuatoriana, tal como lo refiere Marcos (2005). El origen genético del cacao se ubicaría también en lo que hoy es la Amazonía norte del Ecuador (Loor et al. 2012), pero sobre este aspecto no se profundizará en este espacio.

Lo antes señalado da cuenta de la importancia que el cacao ha tenido en la zona geográfica de lo que hoy constituye Ecuador, especialmente en las épocas Colonial, Republicana y Contemporánea, por su trascendencia económica y por ser fuente de identidad cultural (Chiriboga 2013; Guerrero 1980; Maiguashca 2012).

El interés por este producto también llegó a Europa, lo que se observa en el relato respecto del consumo de chocolate como parte de las costumbres de las élites europeas. Así, "la infanta María Teresa de España, al casarse con Luis XIV de Francia, le habría entregado el secreto de la receta de chocolate como regalo de novios" (Sanfuentes Echeverría 2006, 531); posteriormente, el chocolate sería declarado la bebida oficial de la corte francesa.

Específicamente en el caso del Ecuador, Manuel Chiriboga (2013), en Jornaleros, grandes propietarios y exportación cacaotera, 1790-1925, se refiere a la incidencia de este producto en la historia del Ecuador, principalmente a finales del siglo XVIII y principios del XX, en la época de la "pepa de oro", ${ }^{1}$ y explora la relación entre los productores de cacao y los trabajadores. Chiriboga (2013) menciona que el primer boom cacaotero se dio entre 1770 y 1842 , dentro del sistema económico latifundista imperante en aquella época, y ofrece cálculos sucintos sobre el volumen de producción y

1. El cacao fino y de aroma es de color verde pero, una vez que madura, su color se torna amarillo; de ahí viene la denominación "pepa de oro” (Chiriboga 2013). 
ganancias. Es de notar que la inserción del cacao en la economía de la Costa ecuatoriana había iniciado un siglo antes.

Hacia 1600 la recolección y explotación de cacao constituía uno de los rubros importantes de actividad de la antigua provincia de Guayaquil. Cerca de nueve barcos salían anualmente del puerto transportando cacao, especialmente a México, luego de la quiebra de la producción guatemalteca hacia 1580. (Chiriboga 2013, 27)

El autor determina cómo la concentración de la propiedad se constituye en el generador de conflictos sociales en las relaciones de producción durante el auge que tuvo el cacao entre los años 1885 y 1912, cuando se dieron condiciones particulares, tales como "la expropiación de las propiedades campesinas en favor de los sectores dominantes, la conformación de las grandes propiedades cacaoteras, la movilización forzada, y el sometimiento a los trabajadores" (Chiriboga 2013, 21-22), todo esto en un contexto desarrollado en la forzada realidad de una vocación agrícola del Ecuador.

Fue en la ciudad de Guayaquil, como centro comercial y bancario del país, donde el cacao se conectó con el mercado mundial y brindó grandes ganancias a los sectores dominantes; no obstante, ya se podían asimilar los factores que generaron la crisis cacaotera del siglo XX. Guayaquil se convirtió en la capital del cacao desde la Colonia, por su posición de puerto que permitía la conexión con otras latitudes.

La política colonial de las grandes empresas monopólicas del chocolate impulsa al cacao en el continente africano, dando como resultado: el enfrentamiento, la competencia entre productores africanos y agroexportadores ecuatorianos; la vertiginosa caída de los precios [...]. La Primera Guerra Mundial vendrá a oscurecer más el panorama; la época de la deflación se traducirá en crisis y ruina del régimen agroexportador. (Chiriboga 2013,23)

Según Acosta (2006), en la historia económica del Ecuador, la exportación de la pepa de oro se articuló a una fase económica primaria-exportadora. Por su parte, además hay que considerar la política, que "tuvo una influencia fundamental por el lado del control territorial y social, en el cual se sintetizaban los aspectos ideológicos del permanente conflicto entre dominación oligárquica y participación ciudadana, así como entre poder central y poderes regionales" (Acosta 2006, 29). 
Imagen 1

Hacienda de cacao

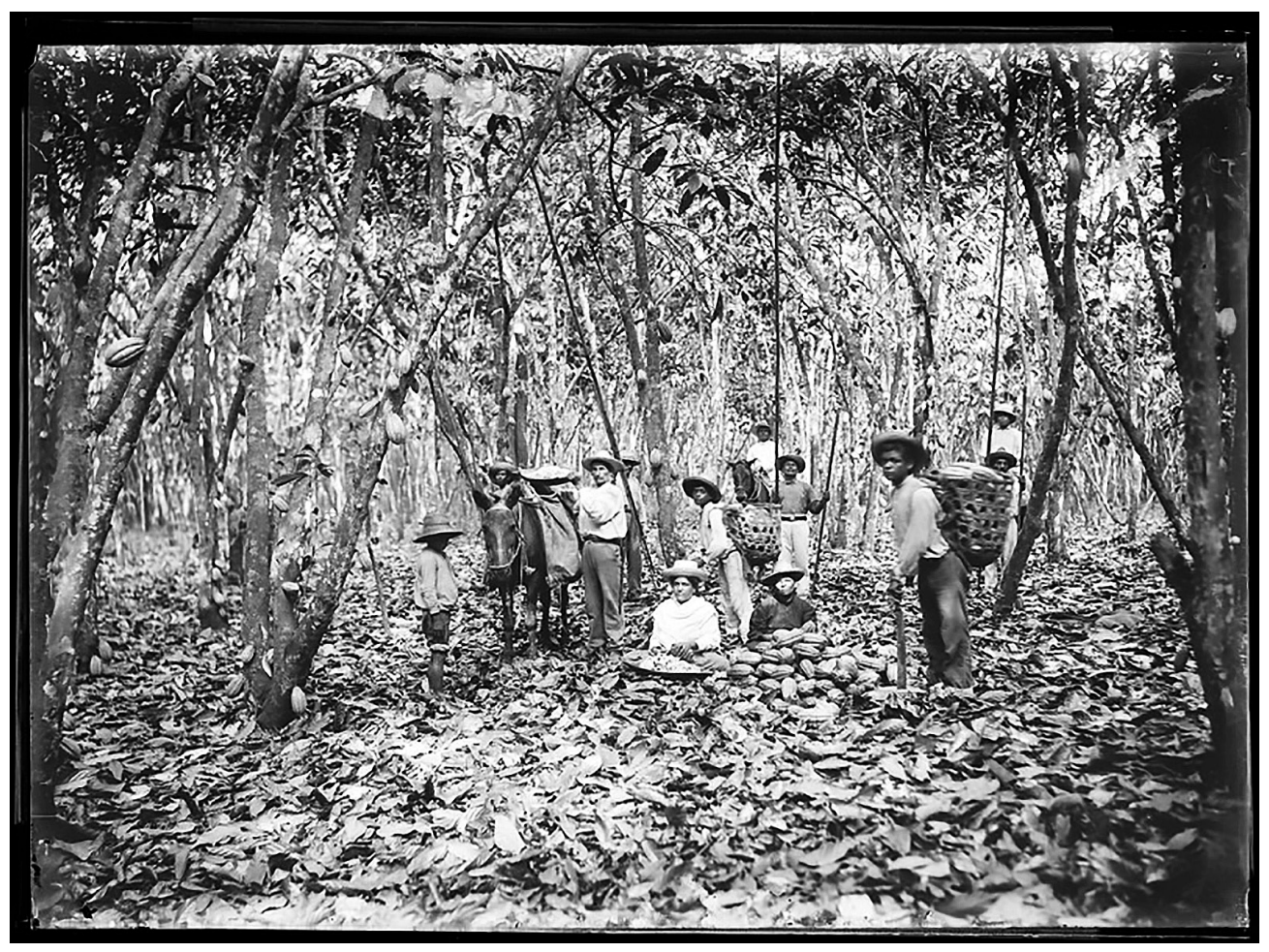

Fuente: Archivo Histórico del Guayas (circa 1900-1909).

El cacao nacional, considerado un grupo genético particular, es la variedad que dio a conocer al Ecuador en el mercado mundial, y es sinónimo de aromas y sabores, características que se deben a las condiciones climáticas y geográficas que posee su zona de producción, y que contribuyen a la denominación de cacao fino y de aroma.

Ecuador, por sus condiciones geográficas y su riqueza en recursos biológicos, es el productor por excelencia de Cacao Arriba fino y de aroma (63\% de la producción mundial), proveniente de la variedad Nacional, cuyo sabor ha sido reconocido durante siglos en el 
mercado internacional. Este tipo de grano es utilizado en todos los chocolates refinados. Sin embargo, los que muchos no saben es que el chocolate fino se distingue por su pureza, específicamente, el sabor y fragancia que el cacao tiene. (Anecacao 2019, párr. 3)

El nombre arriba se origina durante la época de gran producción cacaotera, en el segundo boom del cacao (1870-1930). "Cuenta la historia que los comerciantes llegaban hasta el puerto de Guayaquil para comprar el cacao ecuatoriano y llevárselo a Europa. Al preguntar de dónde traían el producto, la gente respondía que 'de arriba' [...], empezaron a llamarlo Cacao Arriba" (Anecacao 2019, párr. 4).

El distrito de Arriba (provincia de Los Ríos) era el epicentro de la economía cacaotera. $\mathrm{Su}$ producto era de mejor calidad que el de las otras regiones productoras y, por lo tanto, se cotizaba a mayor precio. Su primacía se debió a diversos factores. En primer lugar, el suelo aluvial era excepcionalmente profundo, "probablemente más profundo que en cualquier otro país tropical”. (Maiguashca 2012, 75)

La denominación arriba fue registrada en el Instituto Ecuatoriano de Propiedad Intelectual (IEPI) en 2008, y se obtuvo el sello de denominación de origen (DO) del país en 2014: "Su historia es parte de los retos que tiene la DO, que busca poner en marcha la reactivación de un sector que ha sido maltratado a través de la historia, pero que ha trabajado inclaudicablemente junto a la mazorca de cacao" (EC IEPI 2019, párr. 2).

También se pueden mencionar otras variedades como el cacao criollo, término atribuido a los españoles por los habitantes nativos de la época (Quiroz 2002), y cacao sacha, conocido así en honor a los superárboles de cacao ubicados en la finca de la familia Sánchez, que son de gran productividad y resistencia (Zambrano Aveiga 2013). Su "material genético en nuevas siembras, mediante las labores agrícolas adecuadas, incrementaría el rendimiento por hectárea y permitiría la generación de ganancias a mediano y largo plazo, en lo económico, social y ambiental" (Calva y Ramírez 2016, 5). Finalmente, la variedad más popular y de calidad (aunque no posee el aroma del cacao arriba) es el cacao ramilla o CCN-51 (Colección Castro Naranjal 51). Desarrollado por Homero Castro Zurita, es una variedad del trinitario, el "cual presenta algunas características que le han permitido ganar alguna aceptación entre los cacaoteros ecuatorianos. Su productividad es casi seis veces 
mayor que la de las otras variedades cultivadas en el país, es más resistente a plagas y enfermedades" (Vassallo 2015, 52).

En 1800 se registró una proliferación de fábricas de chocolate en Europa y Estados Unidos, debido, además, a que en esa época el holandés Coenraad Johannes van Houten inventó una prensa hidráulica mediante la cual se pudo obtener cacao en polvo, que se disolvía de mejor manera en el agua caliente y facilitaba la digestión del producto (García Luaces 2014). De esta manera se fomentaron sistemas de producción y comercialización relacionados con esta idea innovadora, aspectos que también impactaron a los proveedores del Ecuador, pues permitieron la expansión de las haciendas productoras de cacao en el litoral ecuatoriano.

Guerrero (1980) señala que los dueños de las tierras para la producción de cacao constituyeron una burguesía local que generó iniciativas empresariales para aprovechar la demanda de bienes y servicios por parte de los consumidores del sistema capitalista mundial. Además, destaca las condiciones favorables de clima, que permitieron generar ventajas comparativas, especialmente en el cultivo de la variedad del cacao fino y de aroma.

Lo antes mencionado provocó que a las familias que acumularon gran fortuna con el cultivo y la exportación cacaotera desde el puerto de Guayaquil, especialmente durante el siglo XIX y principios del XX, se las conociera como "Gran Cacao", dicho producto provenía de las cuencas de los ríos Daule y Babahoyo, afluentes del Guayas. Larrea Maldonado (2006) anota que, a principios del siglo XX, la demanda intensiva de cacao por parte de los países más industrializados ubicó al país en los primeros lugares de exportación en el planeta, con cerca de un $25 \%$ del total de la producción mundial, lo que representaba el 70\% del total de las exportaciones para el país. En el proceso de producción, la inversión de capital fue mínima, y la tecnología utilizada se centraba en el uso extensivo de la tierra, junto con el trabajo no calificado. No obstante, el auge del cacao permitió la construcción de obras para la mayor integración de la nación.

El desarrollo cacaotero conformó las bases para una posterior integración del espacio nacional y el desarrollo de su mercado interno, que se establecieron solamente en la etapa bananera. García Moreno inició la carretera Quito-Guayaquil y Alfaro culminó el ferrocarril en 1908. Ya en 1897 se unieron la carretera y el ferrocarril, facilitando 
las migraciones internas y el tráfico de productos entre la Sierra y la Costa. (Larrea Maldonado 2006, 52)

Chiriboga menciona que el primer auge cacaotero se desarrolló entre los años 1763 y 1840, bajo el impulso de las reformas borbónicas; fue el verdadero boom de la época de los Gran Cacao: "Los Aspiazu, los García Moreno, los Sotomayor, los Carmigniani y los Mendoza" (Chiriboga 2012, 16). Desde el año 1880 se produjo una revalorización de esas tierras.

Por otra parte, en 1840 la Costa del Ecuador fue víctima de epidemias de fiebre amarilla que diezmaron a la población, lo que produjo una ingente pérdida de las cosechas en las haciendas productoras de cacao. Así, esta “crisis cacaotera marca la fragilidad de la integración del Ecuador al mercado mundial sobre la base de productos primarios o monocultivos, con el predominio de tecnologías extensivas y un escaso conocimiento técnico sobre los productos cultivados" (Larrea Maldonado 2006, 57). A pesar de la crisis existente, la abolición del concertaje en 1918 y el control ideológico de los grupos económicos de la Sierra del país provocaron un traslado de la mano de obra hacia la Costa, cuya respuesta fue la expansión de la frontera agrícola, que fomentó la concentración de la tierra y los ingresos de las familias productoras de cacao (Acosta 2006).

Al mismo tiempo, a inicios del siglo XX, se empezó a cultivar cacao en África, lo que disminuyó la competitividad de las exportaciones nacionales; además, dos plagas arrasaron con la producción cacaotera, lo que generó una caída de los precios internacionales (Larrea Maldonado 2006). Esta situación significaría el inicio de una crisis aún peor, "que surgiría por la caída de los precios del cacao, como efecto del ingreso masivo al mercado mundial de cacao originado en la africana Costa de Oro, donde el imperio colonial inglés introdujo en forma forzada el cultivo" (Chiriboga 2012, 20). A ello deben sumarse la crisis financiera de 1929 y la crisis nacional del sistema bancario y financiero, que ocurrieron en la misma época. De este modo, las haciendas ecuatorianas se orientaron a un nuevo modelo de negocio basado en la producción del banano.

Chiriboga (2012) señala que, durante la Primera Guerra Mundial, las relaciones comerciales entre las firmas exportadoras ecuatorianas y varias empresas de los países involucrados en el conflicto bélico se deterioraron debido a los embargos que existían. 
Hay que mencionar que la urdimbre del cacao, que corresponde a la parte histórica y cultural, versa sobre la identidad nacional como un aspecto esencial relacionado con la producción del cacao fino y de aroma, toda vez que se pueden resaltar factores culturales asociados. Por ejemplo, el Acuerdo del Ministerio de Cultura y Patrimonio No. DM-2017-063 incorpora al cacao fino y de aroma como patrimonio cultural inmaterial de la nación, y menciona que Ecuador es el principal productor mundial de este tipo de variedad de cacao; además, señala que es indispensable preservar este legado cultural, social y económico. Por tal razón, el Estado debe procurar medidas para su salvaguardia, lo que "se entiende como un reconocimiento simbólico a la importancia de estos saberes traducidos en prácticas, usos sociales y culturales de varias poblaciones ecuatorianas que han hecho de la producción del cacao su forma de vida" (EC Ministerio de Cultura y Patrimonio 2017, párr. 27). Se considera que las familias dedicadas a la producción agrícola de cacao comparten un conjunto de creencias, valores y costumbres que las identifican como un grupo cultural definido. Con estos antecedentes, se ha logrado determinar una serie de aspectos relativos al sentido histórico y cultural del cacao en Ecuador, que el Estado ha querido rescatar.

Así también, el cacao arriba configuró una identidad propia, situación que se puede visibilizar en la ciudad de Vinces, ubicada en la provincia de Los Ríos y que, junto a Babahoyo, Pueblo Viejo, Palenque, Mocache y Quevedo, era uno de los pueblos en se producía principalmente esta variedad. Allí, el cacao se convierte en un imaginario social que fomenta el orgullo de esta manifestación cultural.

El territorio cacaotero de Vinces, que incluía las parroquias de Palenque, Mocache, Quevedo y la propia Vinces, podía considerarse a inicios del siglo $\mathrm{XX}$ como la capital cacaotera del mundo. Prueba de ello es que para finales del siglo XVIII ya se cultivaban cerca de 145.000 árboles de cacao, "aprovechando condiciones naturales únicas como la presencia de ricos depósitos aluviales, traídos por una densa red fluvial, que incluía ríos como el mismo Vinces, que al conectarse con el Río Guayas, permitía acceso directo a la ciudad puerto de Guayaquil" (Chiriboga 2012, 15).

La vida de los habitantes de Vinces, como resultado de la internacionalización del negocio del cacao, tuvo una influencia cultural, especialmente francesa, materializada en la arquitectura, los vestidos, la comida y el propio 
lenguaje. Esta situación se daba por "un efecto contagio traído por las familias cacaoteras, cuya costumbre era distribuir la residencia de los varios miembros de la familia entre las haciendas, Guayaquil, Londres, París o Berlín, según las conexiones comerciales de las familias" (Chiriboga 2012, 18). Por esta razón se llegó a conocer popularmente a Vinces como "París chiquito", con un imaginario social que permanece hasta la actualidad en manifestaciones arquitectónicas urbanas: la pequeña réplica de la Torre Eiffel en el centro de la ciudad, un castillo y el palacio municipal antiguo (García 2005). La ruina económica, debido a la crisis cacaotera, dio fin a este estilo de vida luego de la Primera Guerra Mundial (Chiriboga 2012).

Como se ha mencionado en los párrafos precedentes, la producción del cacao tuvo influencias culturales y marcó procesos históricos y económicos. Guayaquil fue a principios del siglo XX el puerto de exportación cacaotera más importante del mundo; por lo tanto, es importante resaltar los factores económicos y comerciales que lo permitieron.

\section{La trama: el contexto económico del cacao y chocolate}

Una vez que se ha abordado la urdimbre (los hilos poco visibles que sostienen los diseños de un tejido o un tapiz), se procederá en este punto a describir la trama, que corresponde a los elementos más visibles: para este caso, el contexto económico relacionado con el cacao y el chocolate. Como se ha señalado, la historia del cacao, como producto relevante para la economía ecuatoriana, se remonta a 1779 (primer auge cacaotero). Entre los años 1825 y 1843, su nivel de exportación hacia México, América Central, España y el resto de Europa creció aproximadamente en un 118\% (Chiriboga 2013); a su vez en 1888 las exportaciones de cacao superaron los volúmenes habituales y de esta manera, el cacao se incorporó como producto primario a la economía mundial (Acosta 2006). La bonanza cacaotera y sus crisis determinaron el ciclo de exportación; fue así como, entre 1790 y 1800, hubo alrededor de tres millones de plantas de cacao en la Costa (EC Ministerio Coordinador de Patrimonio 2013). 
La exportación del producto entre 1845 y 1880 no contó con un registro estadístico que pueda ser considerado como certero; sin embargo, de los registros existentes, una fuente relativamente confiable, según señala Chiriboga (2013), es la revista del Mercado de Guayaquil, perteneciente a la casa Martin Reinberg \& Co. Los datos de exportación se aprecian en la figura 1.

Figura 1

\section{Exportaciones en quintales de cacao, 1845-1880}

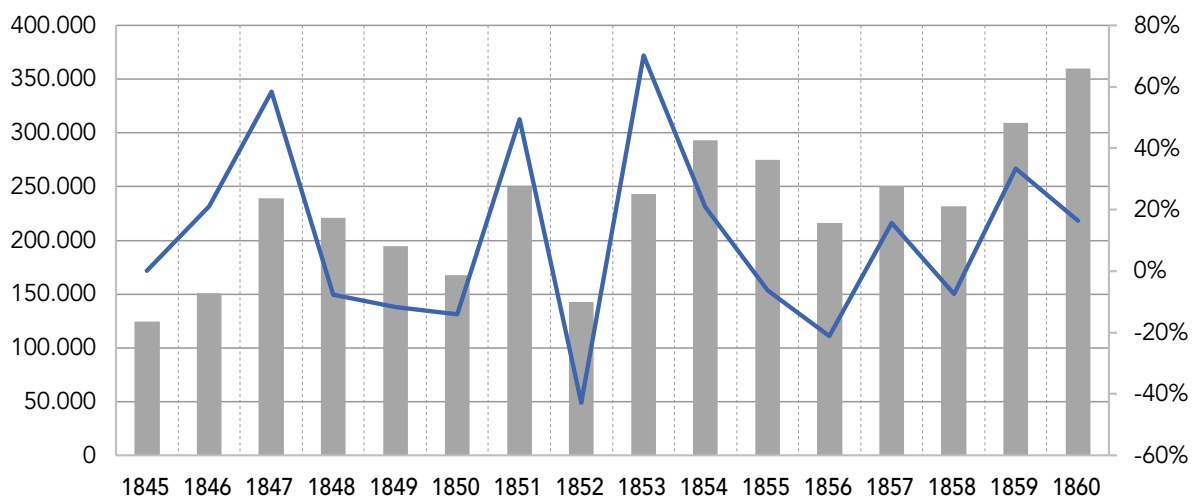

Fuente: Chiriboga $(2013,58)$.

Durante los años de la fiebre amarilla, las exportaciones cayeron sustancialmente y la producción costeña se reorganizó, lo que permitió un nuevo auge cacaotero a finales del siglo XIX. La producción se sustentaba, entre otros aspectos, en el trabajo forzado, la migración de mano de obra desde la Sierra -por la crisis de los obrajes-, procesos productivos rudimentarios, relaciones comerciales inexistentes y la legislación contra la "vagancia" (Acosta 2006; Chiriboga 2013).

El incremento en la producción, sin embargo, requería de un contingente de agricultores que no pudo ser cubierto debido a la crisis demográfica en la región costera durante la época. De todas formas, desde finales de 1870, las exportaciones comienzan a ser representativas y el cacao se vuelve más importante gracias a los siguientes factores: caída de las exportaciones de productos ligados a la elaboración artesanal, aumento de los precios del cacao 
y de la producción cacaotera, cambios en los mercados de destino, transnacionales en busca de materia prima en otras economías, mayores relaciones comerciales, y el uso de tecnologías (Acosta 2006).

Entre 1880 y 1895, Ecuador se convierte en el mayor exportador de cacao. Los factores vinculados con el incremento de las relaciones entre los grupos comerciales guayaquileños y los terratenientes, tanto serranos como costeños, permitieron un incremento en la comercialización de este producto. Estas relaciones constituyen el nacimiento de una burguesía intermedia bajo nuevas relaciones de producción, impulsadas por las modificaciones ideológicas que plantearon los liberales durante esta época (Acosta 2006; Chiriboga 2013).

Henderson (1997) señala que el sistema productivo del cacao no alcanzó durante esa época un gran crecimiento, debido a un casi nulo impulso en el uso de tecnologías para la producción que permitiera a otros sectores desarrollarse por la participación en la agregación de valor. Existía una necesidad de incrementar la productividad de la fuerza laboral como factor fundamental para la producción, aspecto dinámico del capitalismo, pero este atributo no era una característica de la economía ecuatoriana de la época.

Durante los inicios del siglo XX, el cultivo de cacao se centró primordialmente en zonas que determinaran su denominación de origen y que contaran con las condiciones naturales para permitir el crecimiento de la producción cacaotera, así como su comercialización, por encontrarse cercanas a vías fluviales: la zona del río arriba (Vinces), Balao, Machala y la zona de Manabí y Esmeraldas (Chiriboga 2013).

La producción de estas zonas se incrementó paulatinamente durante los años 1877-1925. Sin embargo, fue la zona de arriba la que presentó mayor crecimiento: llegó a tener una cosecha máxima de 703.692 quintales en 1914, el pico de esta tendencia creciente. Posteriormente, la tendencia es decreciente, aspecto que coincide con la Primera Guerra Mundial (Maiguashca 2012).

Durante 1877-1925, Ecuador se constituyó como el líder en la producción de cacao, e incluso el British Chargé d'Affaires (el Encargado de Negocios británico) consideraba en 1914 que si la economía ecuatoriana se hubiera manejado de manera adecuada, el país se habría convertido en el más rico de la costa oeste de Sudamérica (Henderson 1997). 
La zona de arriba tenía aproximadamente el 52\% de los árboles del país. Entre 1877 y 1917, aproximadamente el 60\% del total de la producción cacaotera estuvo constituido por el cacao arriba, mientras que de 1918 a 1925 se aprecia un incremento de aproximadamente el 10\% sobre este valor (Chiriboga 2013).

Los datos del trabajo realizado por Maiguashca (2012), sobre las exportaciones cacaoteras medidas en quintales entre 1881 y 1930 , reflejan el incremento sostenido de estos volúmenes. De igual manera, se aprecia una disminución para el último período, comprendido entre 1921 y 1924.

Tabla 1

Exportaciones cacaoteras del Ecuador, promedios anuales, 1881-1930

\begin{tabular}{|c|c|c|}
\hline Años & Quintales & Incremento \\
\hline $1881-1890$ & 259.939 & - \\
\hline $1891-1900$ & 370.318 & $42,46 \%$ \\
\hline $1901-1910$ & 520.916 & $40,67 \%$ \\
\hline $1911-1920$ & 817.707 & $56,97 \%$ \\
\hline $1921-1924$ & 722.530 & $-11,64 \%$ \\
\hline
\end{tabular}

Fuente: Maiguashca $(2012,78)$.

Se debe señalar que en 1846 existía una clara concentración de la producción cacaotera, pues el $77,7 \%$ de la producción pertenecía solo a dos empresas de un total de ocho competidores; por su parte, en 1915 eran cuatro empresas las que poseían el 74,4\% de la producción, de un total de 24 (Baquero y Mieles 2014). La década de 1920 fue devastadora para la comercialización y producción del cacao, esto debido a una sobreproducción: aunque el consumo creció, el excedente no pudo ser colocado en el mercado y el precio cayó, lo que forzó a la Asociación de Agricultores del Ecuador a intervenir en el mercado (Henderson 1997). ${ }^{2}$

2. Esta asociación fue conformada en 1912 por los principales exportadores de cacao del litoral ecuatoriano con el objetivo de enfrentar la competencia extranjera y controlar el precio del 
En principio, esta intervención coadyuvó a una mejora en los precios; sin embargo, luego volvieron a bajar, aunque el esfuerzo por restaurarlos se mantuvo hasta la desaparición de la asociación en 1925. Su intervención y su interés por regular el precio del cacao se tornó en un mecanismo de especulación nacional, lo que en parte impidió que cumpliera con las metas inicialmente establecidas (Baquero y Mieles 2014).

La producción mundial de cacao dio un giro para Ecuador. Durante 1920, se evidenció una profunda disminución respecto a otros productores: de tener casi un $30 \%$ de la producción en 1894, llegó a tener solo el 6,53\% en 1924. Por otro lado, las colonias británicas se tomaron el mercado: llegaron en 1924 a contar con un 53,54\% del total de la producción mundial (Chiriboga 2013).

La aparición y expansión de enfermedades redujo la producción en un $30 \%$, sumadas a la falta de medios de transporte y de acceso a mercados internacionales como consecuencias de la Primera Guerra Mundial. Así, el cacao y la economía ecuatorianos entraron en un período de depresión e inestabilidad. Conforme la producción fue disminuyendo, como fenómeno combinado con la caída del precio y los problemas de comercialización, la crisis se profundizó y afectó a los grandes propietarios.

El fin de la Primera Guerra Mundial no llevó a una mejora de la situación; todo lo contrario, ya que se buscaba una disminución de los precios de las materias primas para el desarrollo de la industria chocolatera. Esta disminución, además, coincidió con la gran depresión de los años 30 .

La crisis que se presentó en la producción de cacao, que se relacionaba con otros productos y con fenómenos demográficos tanto de la Costa como la Sierra ecuatoriana, no se dio exclusivamente por la disminución del precio internacional de este producto, sino que también se vio afectada por el bajo desarrollo de las fuerzas productivas existentes en ese momento (Chiriboga 2013).

Como reacción a la propagación de la plaga en las plantaciones cacaoteras, se produjo un sinnúmero de denuncias sobre la disminución en el número de quintales cosechados, despidos de trabajadores y solicitud de rebaja del avalúo catastral. Para 1927, se empezó a buscar la siembra de otro tipo de

cacao; esto último, mediante la compra del cacao a los productores, a los precios impuestos por las casas exportadoras independientes (Chiriboga 2013). 
productos que pudieran resultar más rentables en aquellas propiedades que no habían sido embargadas (Maiguashca 2012).

La crisis del cacao llevó a lo que Chiriboga denomina una "crisis del régimen agroexportador y reestructuración de las clases sociales" $(2013,383)$. Los grupos económicos con mayores recursos tuvieron la posibilidad de adquirir las tierras de los agricultores afectados por la crisis y, por lo tanto, se multiplicaron los pequeños productores dedicados a cultivos de yuca, arroz y banano. En 1929, el Banco del Ecuador ya señalaba que este último era el nuevo producto a cultivar.

Figura 2

Cacao como porcentaje del total de exportaciones, 1948-2018

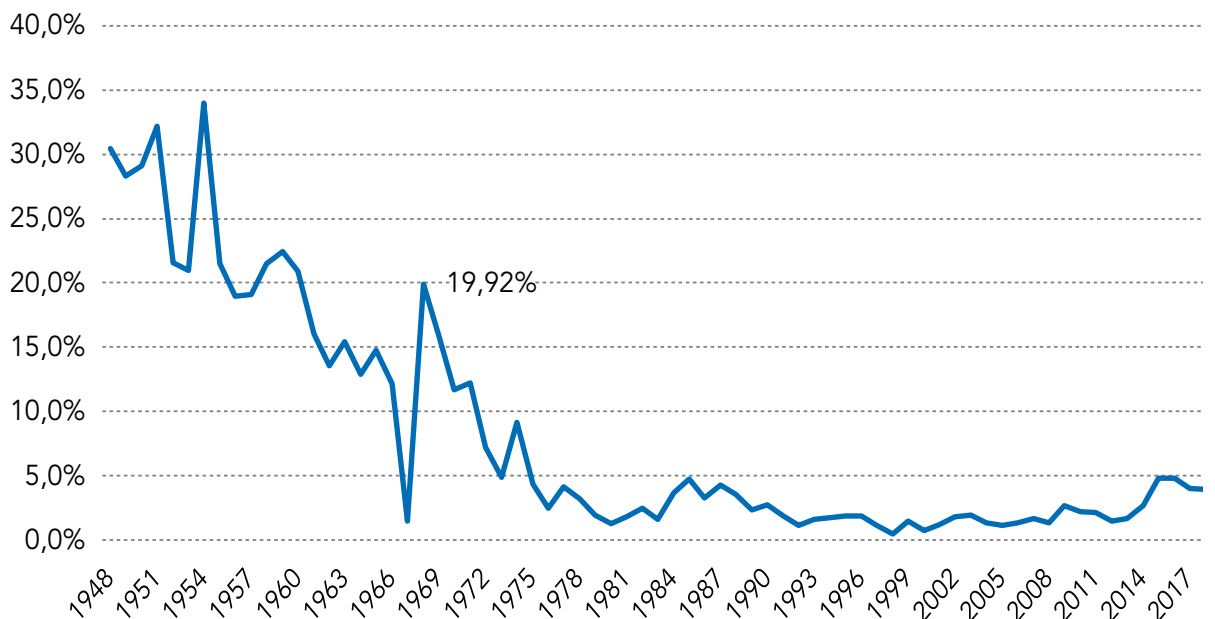

Fuente: Acosta (2006) y Banco Central del Ecuador (2019).

Los volúmenes de exportación del cacao, a partir de 1948, disminuyeron vertiginosamente, y se distinguen tres etapas entre aquel año y 2018. En la primera, de 1948 a 1967, se refleja el mayor nivel de disminución: de 30,46\% sobre el total de exportaciones, a un 1,49\%. La segunda empieza en 1968 con un repunte en el porcentaje de exportaciones, que alcanza un 19,92\% 
debido a condiciones estructurales del mercado; luego, hasta 1998, existe un decrecimiento sostenido que alcanza un 0,45\%. En el tercer período, de 1998 a 2018, se observa un crecimiento en los porcentajes de exportación, sin que sean comparables a los de la época de mayor exportación de la pepa de oro (Acosta 2006; Banco Central del Ecuador 2019).

Tabla 2

Producción mundial de cacao en toneladas métricas (TM), 2016-2017

\begin{tabular}{|c|l|c|}
\hline & \multicolumn{1}{|c|}{ País } & Producción en TM \\
\hline 1 & Costa de Marfil & 2 '010.000 \\
\hline 2 & Ghana & 950.000 \\
\hline 3 & Indonesia & 320.000 \\
\hline 4 & Ecuador & 300.000 \\
\hline
\end{tabular}

Fuente: International Cocoa Organization (2019).

Actualmente, Ecuador es el cuarto productor de cacao a nivel mundial, con 300.000 toneladas al año (tabla 2). El crecimiento ha sido del $110 \%$ durante los últimos diez años, con una cadena de valor que beneficia a 600.000 familias en todo el país (EC Pro Ecuador 2018). Para el 2016, el 80\% del cultivo correspondía a pequeños productores. La provincia de Guayas representaba el 28\% de la producción nacional; Los Ríos, 23\%; y Manabí, 13\% (EC Pro Ecuador 2016).

Para el 2016, se registraron 66 empresas enfocadas en el cultivo de cacao, principalmente ubicadas en Guayas, Pichincha y El Oro, que generaron plazas de trabajo con beneficios para 561 personas. En el mismo período, en la provincia de Pichincha se concentraron 32 empresas, que beneficiaron a 470 personas (EC Corporación Financiera Nacional 2018). Es así como "Ecuador se posiciona como el país más competitivo de América Latina en este campo, seguido de lejos por Venezuela, Panamá y México, que son países que poco a poco han incrementado su participación en el mercado mundial del cacao fino en grano" (Anecacao 2019, párr. 2). En el país se produ- 
cen, entonces, dos variedades principales de cacao, que la organización Pro Ecuador describe como:

Cacao Fino de Aroma [...], cuyo color característico es el amarillo, posee un aroma y sabor único, siendo esencial para la producción del exquisito chocolate gourmet apetecido a nivel mundial. Cacao CCN-51, conocido también como Colección Castro Naranjal, cuyo color característico es el rojo. Además, es reconocido por sus características de alto rendimiento para la extracción de semielaborados, ingredientes esenciales para la producción a escala de chocolates y otros. (EC Pro Ecuador 2016, párr. 4)

Figura 3

Destinos de exportación de cacao, en miles de dólares, 2013-2017

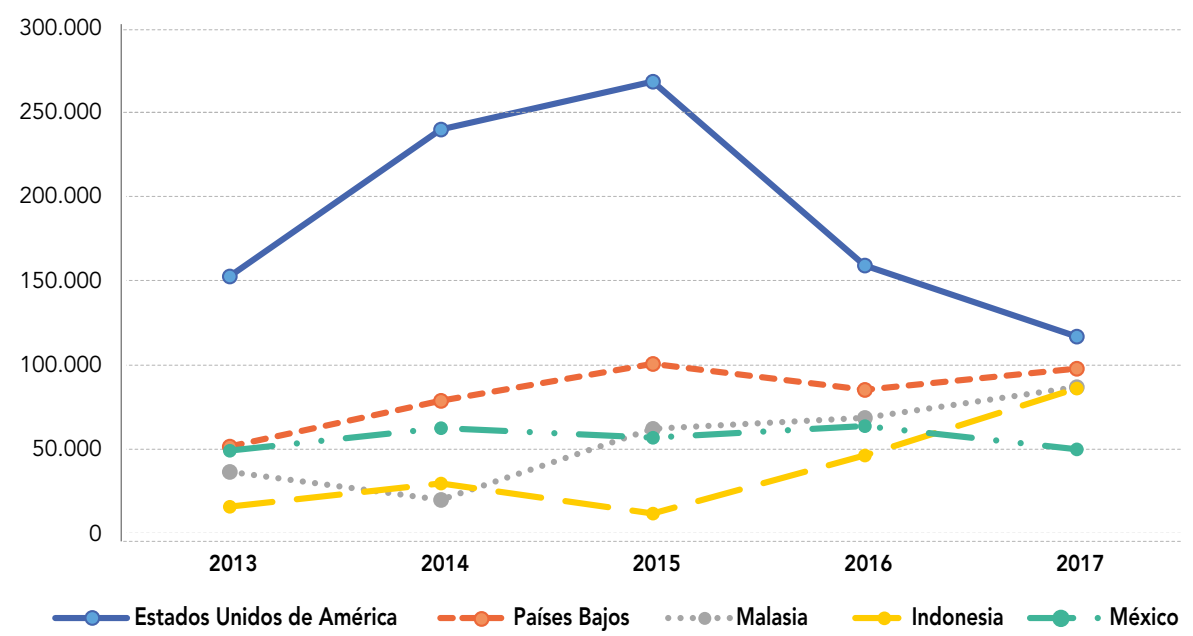

Fuente: United Nations Comtrade (2018).

Según United Nations Comtrade (2018), las exportaciones, a partir del 2001, se diversificaron. Estados Unidos se ha convertido en uno de los destinos de exportación con mayor crecimiento, como se aprecia en la figura 3. Por otra parte, la International Cocoa Organization (ICCO) coordina y pone en marcha el "Acuerdo Internacional del Cacao", firmado en 2010, que busca entre otros objetivos la determinación de precios justos de este producto tanto para productores como para consumidores (2019). 
Figura 4

\section{Precio internacional mensual promedio de cacao, en dólares por tonelada, noviembre de 2019}

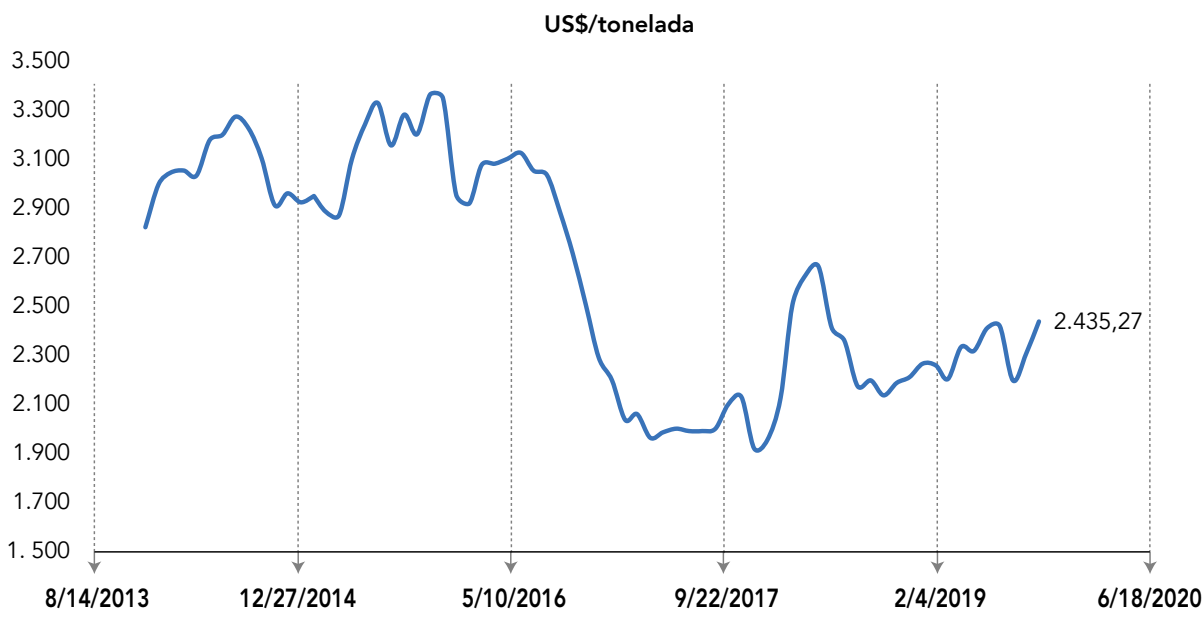

Fuente: International Cocoa Organization (2019).

Según datos de la ICCO (2019), en los últimos años el precio del cacao a nivel internacional ha sido fluctuante, lo que evidentemente afecta el precio del cacao fino de aroma. La figura 4 muestra cómo el precio disminuye a partir de enero de 2016 y durante el 2017 tiene sus valores más bajos. En 2018 inicia con valores bajos y luego se eleva hasta mayo, para posteriormente iniciar otro descenso.

Se considera necesario generar otros elementos que permitan mejorar la producción y capacidad de exportación del cacao, toda vez que actualmente se lo exporta en tres diferentes productos referidos a las diversas etapas de elaboración: granos de cacao, productos semielaborados y productos terminados, como las clásicas barras de chocolate, cuyo sustancial valor agregado viene dado por su calidad organoléptica.

Como se ha señalado a lo largo de este texto, por medio de la metáfora del tejido, dos elementos han sido considerados como objetos de análisis: la cultura y la economía. La economía ha contribuido a la configuración de 
una identidad ligada a un producto primario como el cacao; esta identidad se nutre de elementos culturales tanto propios como foráneos y establece una forma particular de relacionamiento entre exportadores y productores.

\section{Consideraciones finales}

Este trabajo permitió establecer los principales elementos de los aspectos culturales y económicos relacionados con el cacao en el litoral ecuatoriano. De este modo, se caracterizaron de forma simultánea el significado cultural y el contexto económico, para contar con una mirada doble de dicho objeto de análisis, todo esto por medio de la metáfora como instrumento de acercamiento a estas dos dimensiones.

La trascendencia de la dimensión cultural del cacao se articula con la del aspecto económico; la metáfora del tejido permite contar con una aproximación inicial a estas relaciones. La urdimbre, que es la parte menos visible pero la más fuerte del tejido, se refiere al significado histórico y cultural del cacao, cuya planta, según señalan revelaciones científicas recientes, fue domesticada por primera vez en lo que hoy es Ecuador, hace más de 5.300 años. El significado histórico-cultural se vio fortalecido en los períodos de crecimiento y decadencia de la producción cacaotera, ya que en ellos se configuraron la cultura y las costumbres de las zonas productoras, lo que fue determinante en la estructuración de clases de lo que era la antigua Costa ecuatoriana, con características que aún pueden ser apreciadas.

La trama, que es lo que más visible en un tejido, tiene relación con los datos económicos del cacao, que ha sido un factor clave para comprender la historia económica de este país. El mercado actual del cacao presenta oportunidades económicas para el Ecuador, y su beneficio estriba en la posibilidad de generar alternativas para ampliar su producción para la exportación. Es decir, no solo contar con los cultivos basados en las características geográficas - que le brindan en efecto un gran valor al producto, y que se constituyen en una ventaja comparativa-, sino, a su vez, aportar a la conservación de un árbol que ha contribuido a la generación de una identidad nacional, especialmente en el litoral ecuatoriano, y al mismo tiempo conservar las características organolépticas que otorgan valor a un producto de exportación: 
el cacao fino y de aroma y sus derivados. En la actualidad, Ecuador lidera la producción mundial del cacao fino y de aroma, con más del 70\% del volumen total, situación que ha permitido al país mantener su estatus como uno de los mayores exportadores, y que a su vez ha generado una serie de fortalezas para la implementación de emprendimientos coligados a este producto agrícola. Finalmente, este trabajo de investigación es un aporte al campo de la gestión, ya que plantea la posibilidad de alcanzar una comprensión de elementos culturales que subyacen en las organizaciones -y que por tanto son menos visibles-, para combinarlos con datos económicos, que usualmente se encuentran en los análisis de las estructuras productivas.

\section{Referencias}

Acosta, Alberto. 2006. Breve historia económica del Ecuador. Quito: Corporación Editora Nacional.

Anecacao. 2019. "Cacao nacional". Anecacao. Accedido 2 de marzo de 2019. https://bit.ly/ 2tFra8j

Banco Central del Ecuador. 2019. "Información estadística mensual No. 2003. Enero 2019”. Banco Central del Ecuador. Accedido 26 de febrero de 2019. https://bit.ly/2Qf2Rqq

Baquero, Daniel, y José Mieles. 2014. "Los ‘booms' en perspectiva: cacao y banano”. Foro Economía Ecuador. Accedido 27 de febrero de 2019. https://bit.ly/2Q6KJza

Calva, Alcides, y Pedro Ramírez. 2016. Guía técnica para el establecimiento y manejo del cacao súper árbol. Quito: GIZ.

Chiriboga, Manuel. 2012. "Vinces en la época del cacao". En Un relato del cacao: tempranas imágenes de Los Ríos, editado por Ministerio Coordinador de Patrimonio, 15-21. Quito: Ministerio Coordinador de Patrimonio.

---. 2013. Jornaleros, grandes propietarios y exportación cacaotera, 1790-1925. Quito: Universidad Andina Simón Bolívar, Sede Ecuador / Corporación Editora Nacional.

EC Corporación Financiera Nacional. 2018. "Ficha sectorial: cacao y chocolate". Corporación Financiera Nacional. Accedido 2 de marzo de 2019. https://bit.ly/2KqRIiX

EC Instituto de Propiedad Intelectual (IEPI). 2019. "Cacao Arriba, la Pepa de Oro". Instituto de Propiedad Intelectual. Accedido 20 de enero de 2019. https://bit.ly/2RetDiM

EC Ministerio Coordinador de Patrimonio. 2013. Cacao: el fino de aroma de nuestra identidad. Quito: Ministerio Coordinador de Patrimonio.

EC Ministerio de Cultura y Patrimonio. 2017. Acuerdo Ministerial No. DM-2017-063. Quito: Ministerio de Cultura y Patrimonio. Accedido 20 de enero de 2019. https://bit.ly/36etvEp 
EC Pro Ecuador. 2016. “Alimentos frescos, semielaborados y elaborados”. Pro Ecuador. Accedido 2 de marzo de 2019. https://bit.ly/2q9WsCt

---. 2018. “Cacao, café y elaborados". Pro Ecuador. Accedido 2 de marzo de 2019. https://bit. ly/36e $1 \mathrm{Pj} 5$

García, Charles J. 2005. Compendio histórico San Lorenzo de Vinces. Vinces: Ediciones Culturales Tierra Viva.

García Luaces, Pedro. 2014. “Cacao, el sabor que conquistó al mundo”. Historia y Vida (555): 54-63. https://bit.ly/36ZH1xt

Guerrero, Andrés. 1980. Los oligarcas del cacao: ensayo sobre la acumulación originaria en el Ecuador. Hacendados, cacaoteros, banqueros, exportadores y comerciantes en Guayaquil, 1890-1910. Quito: El Conejo.

Henderson, Paul. 1997. "Cocoa, Finance and the State of Ecuador, 1895-1925”. Bulletin of Latin American Research 16 (2): 169-186. https://doi.org/10.1016/S0261-3050(96)00011-3

International Cocoa Organization (ICOO). 2019. "ICCO Monthly Averages of Daily Prices". International Cocoa Organization. Accedido 20 de enero de 2019. https://bit.ly/33DBv19

Larrea Maldonado, Carlos. 2006. Hacia una historia ecológica del Ecuador: propuestas para el debate. Quito: Universidad Andina Simón Bolívar, Sede Ecuador / Corporación Editora Nacional.

Loor, Rey, Olivier Fouet, Brigitte Courtois y Ange Marie Risterucci. 2009. "Tracing the Native Ancestors of the Modern Theobroma Cacao L. Population in Ecuador". Tree Genetics \& Genomes 5 (3): 421-433. https://doi.org/10.1007/s11295-008-0196-3

Loor, Rey, Olivier Fouet, Arnaud Lemainque, Sylvana Pavek, Michel Boccara, Xavier Argout, Freddy Amores, Brigitte Courtois, Ange Marie Risterucci y Claire Lanaud. 2012. "Insight into the Wild Origin, Migration and Domestication History of the Fine Flavour Nacional Theobroma cacao L. Variety from Ecuador". Plos One 8 (2): 1-11. https://doi. org/10.1371/journal.pone.0048438

Maiguashca, Juan. 2012. "La incorporación del cacao ecuatoriano al mercado mundial entre 1840 y 1925, según los informes consulares". Procesos: revista ecuatoriana de historia 1 (35): 67-98. https://bit.ly/2qa8WtN

Marcos, Jorge. 2005. Los pueblos navegantes del Ecuador prehispánico. Quito: Abya-Yala.

Morgan, Gareth. 1990. Imágenes de la organización. Madrid: RA-MA.

Quiroz, James. 2002. “Caracterización molecular y morfológica de genotipos superiores con características de cacao nacional (Theobroma cacao L.) de Ecuador". Tesis de posgrado, Centro Agronómico Tropical de Investigación y Enseñanza, Turrialba. https://bit. ly/3555Nuh

Sanfuentes Echeverría, Olaya. 2006. "Europa y su percepción del nuevo mundo a través de las especies comestibles y los espacios americanos en el siglo XVI". Historia 39 (2): 531-556. https://bit.ly/372zWMA

Tolila, Paul. 2007. Economía y cultura. Ciudad de México: Consejo Nacional para la Cultura y las Artes. 
United Nations Comtrade. 2018. "Lista de los mercados importadores para un producto exportado por Ecuador. Producto cacao". United Nations Comtrade. Accedido 2 de marzo de 2019. https://bit.ly/2QeLMgw

Vassallo, Miguel. 2015. Diferenciación y agregado de valor en la cadena ecuatoriana del cacao. Quito: IAEN.

Zambrano Aveiga, María Leonor. 2013. "Sobre el origen de las certificaciones, el desarrollo sostenible y los productores de pequeña escala de cacao en la Amazonía ecuatoriana". Tesis de maestría, FLACSO, Quito. https://bit.ly/32DN1Hq

Zarrillo, Sonia, Nilesh Gaikwad, Claire Lanaud, Terry Powis, Christopher Viot, Isabelle Lesur, Olivier Fouet, Xavier Argout, Erwan Guichoux, Franck Salin, Rey Loor Solórzano, Olivier Bouchez, Hélène Vignes, Patrick Severts, Julio Hurtado, Alexandra Yépez, Louis Grivetti, Michael Blake y Francisco Valdez. 2018. "The Use and Domestication of Theobroma Cacao during the mid-Holocene in the Upper Amazon". Nature Ecology \& Evolution 2: 1879-1888. https://go.nature.com/2Qj3vU2 